\title{
Autonomous Learning: Manifestasi Merdeka Belajar Bahasa di Prodi Pendidikan Bahasa Arab
}

\author{
Eva Iryani \\ Universitas Jambi, Jambi, Indonesia \\ Evairyani@unja.ac.id \\ Muhammad Sobri \\ Universitas Jambi, Jambi, Indonesia \\ muhammadsobri@unja.ac.id \\ Friscilla Wulan Tersta \\ Universitas Jambi, Jambi, Indonesia \\ friscillawulant@unja.ac.id
}

\begin{abstract}
This study aims to provide several exposures and indicators regarding student perceptions of autonomous learning in increasing the students' language capacity. In addition, this research is expected to be able to describe several views and in-depth efforts of the participants in increasing their language capacity independently. Mixed-Method was utilized in this study in order to enrich the data both quantitative and qualitative. As a result, the data generated can be more comprehensive in exploring the problem. For quantitative data, the questionnaire was adopted from Khem Raj Joshi (2011) which includes: learner awareness, self-effort, broader autonomous activities, self- esteem, use of reference materials, motivation, and use of technology in learning. Furthermore, for qualitative data, the interview was gathered in order to know the students' arguments related to their reason for being autonomous learners based on the questionnaire. The result of the study found that students have a high level of autonomy in the use of technology in
\end{abstract}


learning. Vice versa, the students categorize as a low level of autonomy based on the indicator of motivation in which they are seldom to give the reward for themselves.

Keyword: Autonomous Learning, Independence Study, Language Capacity

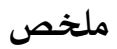

$$
\begin{aligned}
& \text { تهدف هذه الدراسة إلى تقديم بعض التعرضات والمؤشرات المتعلقة بتصهورات الطلاب حول التعلم }
\end{aligned}
$$

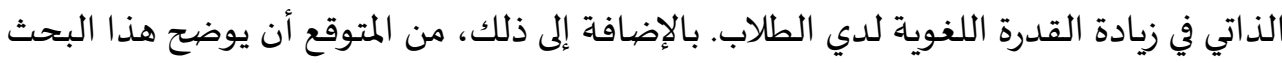

$$
\begin{aligned}
& \text { بعض وجهات نظر المشاركين وجهودهم المتعمقة في زيادة قدراتهم اللغوية بشكل مستقل. }
\end{aligned}
$$

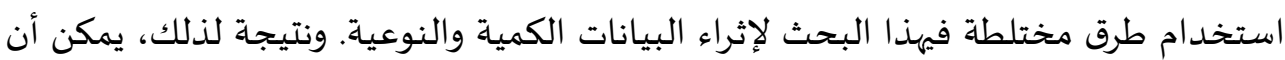

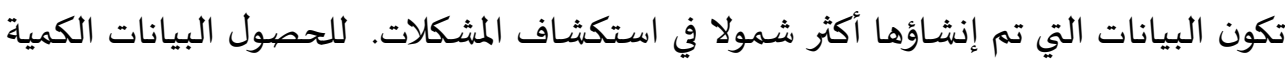

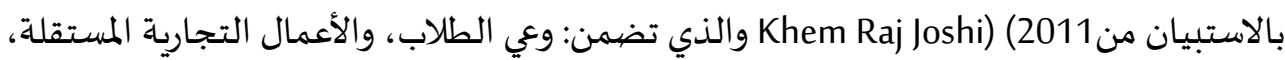

$$
\begin{aligned}
& \text { والأنشطة المستقلة الأوسع، واحترام الذات، واستخدام المواد المرجعية، والتحفيز، واستخدام }
\end{aligned}
$$

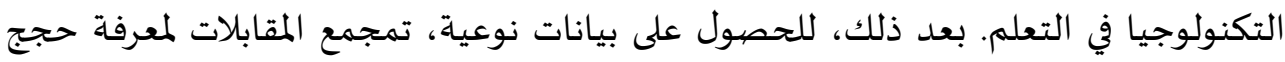

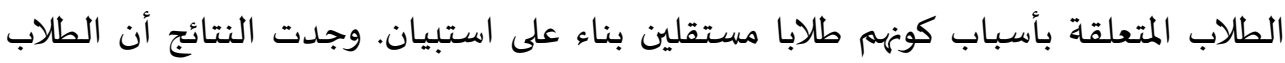

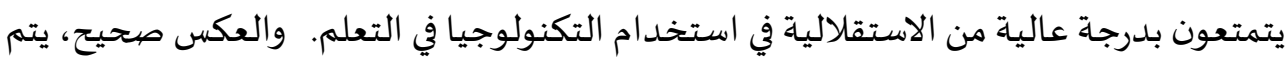

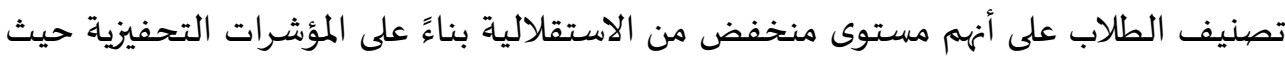

$$
\begin{aligned}
& \text { نادرًا ما يقدمون الهدايا لأنفسهم. } \\
& \text { الكلمات الرئيسية: التعلم الذاتي؛ والتعلم المستقل؛ والقدرة اللغوية }
\end{aligned}
$$

\begin{abstract}
Abstrak
Penelitian ini bertujuan untuk memberikan beberapa paparan dan indikator mengenai persepsi siswa tentang Autonomous Learning dalam meningkatkan kapasitas bahasa siswa.Selain itu, penelitian ini diharapkan dapat menggambarkan beberapa pandangan dan upaya mendalam dari para peserta dalam meningkatkan kapasitas bahasa mereka secara mandiri.Mixed Metods metode digunakan dalam penelitian ini untuk memperkaya data baik kuantitatif dan kualitatif.Alhasil, data yang dihasilkan bisa lebih komprehensif dalam mengeksplorasi masalah. Untuk data kuantitatif, kuesioner diadopsi dari Khem Raj Joshi (2011) yang meliputi: kesadaran pelajar, usaha mandiri, kegiatan otonom yang lebih luas, harga diri, penggunaan bahan referensi, motivasi, dan penggunaan teknologi dalam pembelajaran. Selanjutnya, untuk data kualitatif, wawancara dikumpulkan untuk mengetahui argumen siswa terkait dengan alasan mereka menjadi pelajar mandiri berdasarkan kuesioner.Hasil penelitian menemukan bahwa siswa memiliki otonomi tingkat tinggi dalam penggunaan teknologi dalam pembelajaran.Begitu juga sebaliknya, para siswa dikategorikan sebagai tingkat otonomi yang rendah
\end{abstract}


berdasarkan indikator motivasi di mana mereka jarang memberikan hadiah untuk diri mereka sendiri.

Kata Kunci :Autonomous Learning, Merdeka Belajar dan Kapasitas Bahasa

\section{A. Pendahuluan}

Paradigma pendidikan di Indonesia telah banyak mengalami beberapa perubahan, salah satu contohnya yaitu dari yang dulunya semua proses pembelajaran berpusat pada guru (teacher centred) hingga saat ini terpusat pada siswa (students centered) itu sendiri. Perubahan paradigma ini tentunya banyak mengalami perdebatan, karena hal ini sudah jelas tertuang dalam kurikulum Pendidikan Indonesia menuntut semua elemen pendidikan untuk berpusat pada siswa.

Ditambah lagi, guru-guru di Indonesia jelas berada dalam ambang batas dilema tentang bagaimana mengambil peran dalam perdebatan ini. Di satu sisi, guru perlu mengubah cara mengajar mereka menjadi cara yang lebih modern (berpusat pada siswa); sedangkan faktanya, jika melihat situasi yang dihadapi guru-guru Indonesia, ternyata pembelajaran yang terpusat pada siswa itu masihsulit untuk diterapkan (Dewi, 2017). Akibatnya, kurikulum terus berubah dan guru cenderung menggunakan metode yang sama. Sebaliknya, kesadaran siswa untuk belajar tidak sesuai dengan kurikulum yang diharapkan.Beberapa siswa di Indonesia belajar bukan karena belajar, tetapi untuk menekankan pada hasil terakhir yaitu mendapatkan nilai atau IPK yang baik.

Guru berada pada zona nyaman mereka, sementara siswa tidak memiliki kesadaran mengapa mereka belajar. Dengan demikian, fenomena ini menjadi tradisi bagi guru dan siswa di Indonesia tentang suatu proses belajar mengajar. Fosilisasi ini membawa kesulitan bagi beberapa pelaku pendidikan.Hal ini didukung oleh (Karea, 2016) yang mengatakan bahwa Indonesia memiliki masalah besar dalam mengimplementasikan kurikulum, sedangkan guru memiliki masalah terkait perilaku.Begitu juga sebaliknya, jika dibandingkan dengan AS, sebagian besar sekolah di Indonesia sangat mirip dengan "fenomena kelas pekerja." Pendekatan yang berpusat pada guru banyak digunakan; anak-anak harus mengikuti instruksi guru, diskusi atau inisiatif yang sangat terbatas dan inisiatif dan kreativitas (Karea, 2019) dan salah satu anggapannya adalah karena dipengaruhi oleh peninggalan kolonial (Rachmawati, 2014).

Untuk menunjang kemampuan siswa dalam berkomunikasi, siswa perlu mengatur secara mandiri dan mengarahkan pembelajaran mereka sendiri di 
dalam dan di luar sekolah tempat mereka berada.(Harmer, 2007) berpendapat bahwa untuk mengimbangi batas waktu kelas dan meningkatkan peluang keberhasilan pembelajaran dan pengembangan bahasa, siswa perlu termotivasi untuk mengembangkan strategi belajar mereka sendiri sehingga mereka menjadi pelajar mandiri (autonomous learner).

Oleh karena itu, konsep otonomi dalam pembelajaran harus dibahas lebih lanjut, terutama dalam hal persepsi siswa tentang hal itu.Persepsi siswa tentang otonomi belajar memang sangat penting untuk membangun konsep guru dan pelaku pendidikan lainnya dalam menstimulusi siswa untuk menjadi pembelajara yang mandiri.Pengalaman para siswa tentang pandangan, reaksi, dan perilaku telah berguna secara khusus dalam membangun pemahaman yang besar tentang mereka.Dalam situasi ini, masalahnya ternyata adalah pemahaman siswa tentang otonomi pelajar. Setiap siswa mungkin memiliki perspektif dan cara bereaksi yang berbeda terhadap aspek-aspek tertentu. Selain itu, (Ajzen, 2005) berpendapat bahwa apa yang seseorang yakini tentang suatu fenomena (mis., Konsepsi mereka) memengaruhi harapan atau tujuan mereka.

Keberhasilan pembelajaran otonom dalam konteks Asia terbukti di Vietnam. Penelitian dari Phan (2013), yang menyelidiki tentang Mengembangkan Otonomi di Kelas Asia Timur: dari Kebijakan ke Praktik juga berkaitan dengan masalah bagaimana guru-guru Asia Timur menumbuhkan pembelajaran mandiri siswa mereka di ruang kelas. Selain itu, (Kenny, 1993) percaya bahwa pendidikan tidak akan terjadi tanpa otonomi. Sesuai dengan tren global, Vietnam telah mengidentifikasi pengembangan otonomi pelajar (autonomous learning) sebagai salah satu strategi utama pendidikan tinggi.Vietnam telah mengakui "otonomi" sebagai hasil utama yang dimiliki para lulusan perguruan tinggi.Ini telah secara kuat dinyatakan dalam undangundang pendidikan tinggi negara tahun 2013.Dalam hal bahasa Inggris sebagai jurusan, lulusan universitas diharuskan untuk menjadi pengguna mandiri, yang secara jelas diumumkan dalam "Proyek Pengajaran dan Pembelajaran Bahasa Asing Nasional hingga 2020". Oleh karena itu, mendorong otonomi pelajar, khususnya demi membantu siswa untuk mengidentifikasi tujuan haruslah melaksanakan model dan strategi efektif dan inovatifdemi mencapai tujuan belajar, tampaknya menjadi tugas "harus" bagi universitas Vietnam.

Berangkat dari keadaan tersebut penelitian ini ditujukan untuk mengemukakan dan mengungkap secara menyeluruh persepsi siswa tentang otonomi belajar. Selanjutnya, otonomi pembelajaran yang diekspos dalam penelitian ini akan diarahkan kepada mahasiswa program studi Bahasa Arab 
pada Fakultas Keguruan Ilmu Pendidikan (FKIP) Universitas Jambi. Berdasarkan hasil investigasi awal yang dilakukan peneliti kepada mahasiswa Bahasa Arab, ditemukan bahwasanya hanya 2 dari 10 siswa yang pernah belajar Bahasa Arab pada pendidikan mereka sebelumnya. Seperti maahsiswa yang berasal dari Pondok Pesantren, mereka lebih cenderung terbiasa dengan bahasa Arab.Hal ini tentunya menjadi suatu permasalahan, karena kecenderungan pada prodi tersebut. Mahasiswa lebih banyak bukan berasal dari pondok pesantren yang berlatar belakang dari bukan pondok pesantren dan bahkan tidak pernah mendapatkan pembelajaran bahasa Arab pada pendidikan sebelumya.

Melihat fenomena itu, penting penelitian ini diajukan guna mengungkap bagaimana persepsi siswa dalam autonomous learning (pembelajaran mandiri/ otonomi dalam pembelajaran), agar terlihat bagaimana keterlibatan siswa dari dalam dirinya untuk menunjang kapasitas merekas selaku mahasiswa bahasa Arab dalam menguasai dan mempelajari bahasa Arab tersebut.

\section{B. Pembahasan}

\section{Otonomi dalam Belajar (Autonomous Learning)}

a. Konsepsi Otonomi dalam Belajar

Littlewood (1999) mengusulkan dua fitur utama peserta didik otonom termasuk dalam definisi yang diusulkan oleh peneliti sebelumnya: 1) Siswa harus bertanggung jawab atas pembelajaran mereka sendiri. Ini baik karena semua pembelajaran dapat dalam hal apapun hanya dilakukan oleh siswa sendiri dan juga karena mereka perlu mengembangkan kemampuan untuk melanjutkan pembelajaran setelah akhir pendidikan formal mereka. (2) 'Bertanggung jawab' melibatkan peserta didik yang mengambil kepemilikan (sebagian atau total) dari banyak proses yang secara tradisional menjadi milik guru, seperti memutuskan tujuan pembelajaran, memilih metode pembelajaran, dan mengevaluasi proses. Selain itu, kriteria peserta didik bahasa yang baik saling terkait dengan peserta didik mandiri.

Sejalan dengan itu, Sinclair (2000) menyarankan 13 aspek dalam mendefinisikan otonomi pelajar: (1) Otonomi adalah konstruk kapasitas, (2) Otonomi melibatkan kemauan dari pihak pelajar untuk bertanggung jawab atas pembelajaran mereka sendiri, (3) ) Kapasitas dan kemauan peserta didik untuk memikul tanggung jawab tersebut belum tentu bawaan, (4) Otonomi lengkap adalah tujuan idealis, (5) Ada derajat otonomi, (6) Derajat otonomi tidak stabil dan variabel, (7) 
otonomi bukan hanya masalah menempatkan peserta didik dalam situasi di mana mereka harus mandiri, (8) Mengembangkan otonomi membutuhkan kesadaran secara sadar akan proses pembelajaran yaitu refleksi sadar dan pengambilan keputusan, (9) Mempromosikan otonomi bukan hanya masalah strategi pengajaran, (10) Otonomi dapat terjadi baik dikuar dan didalam kelas (11) Otonomi mempunyai dimensi sosial maupun individu, (12) Promosi otonomi memiliki dimensi politik dan psikologis, (13) Otonomi y ditafsirkan secara berbeda oleh budaya yang berbeda

Dickinson (1987) juga merujuk pada konsepsi yang sama. Dia memandang otonomi sebagai "mode pembelajaran; satu di mana individu bertanggung jawab untuk semua keputusan yang terkait dengan pembelajarannya, dan melakukan implementasi dari keputusan ini ". Baginya, itu adalah tanggung jawab penuh untuk pembelajaran yang dilakukan tanpa investasi guru atau materi pedagogik.

Lebih lanjut, Benson dan Voller (1997) menekankan, istilah 'Belajar Otonomi' mulai digunakan setidaknya dalam lima cara berikut: situasi di mana peserta didik sepenuhnya belajar sendiri; seperangkat kompetensi dan keterampilan dapat diterapkan dan dipelajari sendiri, kapasitas dasar ditingkat melalui institusi, melatih bertanggung jawab atas pembelajaran mandiri dan peserta didik berhak menetapkan arah belajar mereka secara otonomi.

b. Realisasi Otonomi Pembelajaran

Kemandirian belajar dipandang sebagai bidang yang luas. Oleh karena itu, Benson (2007) sebagaimana dikutip dalam Joshi (2011) menjelaskan dua bidang realisasi otonomi pembelajaran, sebagai berikut:

1) Otonomi di luar Ruang Kelas

Ada tujuh aspek yang menjelaskan otonomi di luar kelas; Pertama, Akses Mandiri: Untuk mendorong otonomi, berbagai pusat akses mandiri telah didirikan di seluruh dunia. Pusat-pusat ini menyediakan materi yang diperlukan di mana peserta didik bekerja sendiri untuk belajar. Kedua, Pembelajaran Bahasa Berbantuan Komputer (CALL): Komputer dan teknologi internet telah memainkan peran penting dalam pembelajaran. CALL sebagai produk dari instrumen-instrumen ini telah memfasilitasi pembelajaran mandiri. Ini adalah program belajar sendiri 
menggunakan komputer. Ketiga, pembelajaran jarak jauh: Pembelajaran jarak jauh, mode belajar mandiri tanpa kendala formal, juga mencerminkan karakteristik pembelajaran mandiri. Keempat, Belajar tandem: Belajar tandem, di mana dua orang saling belajar ', bahasa berfungsi untuk saling membantu, telah lama dikaitkan dengan otonomi.

Kelima, belajar diluar Negeri: Dalam program ini siswa menghabiskan waktu di komunitas bahasa target. Meskipun banyak program melibatkan pengajaran di kelas, tujuan utama mereka biasanya bagi siswa untuk belajar secara mandiri melalui interaksi dengan penutur asli. Keenam, Pembelajaran di luar Kelas: Beberapa penelitian menunjukkan bahwa siswa cenderung lebih sering melakukan kegiatan belajar di luar kelas daripada yang diketahui oleh guru mereka. Terakhir, Self-Instruction: Ini merujuk pada penggunaan bahan belajar mandiri yang dicetak atau disiarkan secara independen dari para guru dan dengan demikian, menjadi faktor otonomi di luar kelas.

2) Otonomi di dalam Kelas

(Benson, 2007) sebagaimana dikutip dalam (Joshi, 2011) menjelaskan bahwa peserta didik tidak hanya ditemukan mandiri didalam kelas juga ada diluar kelas.Dalam definisi otonomi luas, ini melingkupi semua keputusan yang dibuat oleh pesertadidik dalam pembelajaran mereka sendiri.Jadi, semua kegiatan, rencana dan tindakan yang pelajar pilih sendiri, membantu mempromosikannya. Di dalam kelas, itu mungkin melibatkan berbagai tingkat kontrol seperti: manajemen untuk pembelajaran, proses kognitif dan konten pembelajaran. Hal ini dapat tercermin dalam kerja kelompok, pembelajaran kooperatif, pembelajaran inovatif atau tindakan dan kegiatan kelas lainnya. Jadi, seorang pembelajar mungkin mencari berbagai cara untuk menjadi otonom dalam suatu kelas. Mereka dapat mencari peluang untuk mempelajari sesuatu dengan lebih mudah, yaitu mempelajari cara belajar. Singkatnya, dapat dikatakan bahwa kelas juga merupakan konteks di mana otonomi pelajar dipraktikkan setidaknya untuk belajar belajar.

Selain itu, peran guru dalam mempromosikan otonomi siswa sangat penting.Untuk mencapai tujuan beberapa hal perlu dipertimbangkan. Menurut (Camilleri, 1997), para guru pelajar 
mandiri harus: Pertama, menyadari pengaruh pribadi mereka sendiri pada proses pembelajaran. Mereka sadar akan keyakinan, sikap, keterampilan, dan praktik mereka sendiri yang berkaitan dengan otonomi. Mereka sadar akan pengalaman belajar mereka sendiri dan tingkat otonomi mereka sebagai pelajar; mereka tahu karakteristik afektif dan kognitif siswa mereka dan sikap serta keterampilan mereka terkait dengan otonomi.

Kedua, pahami pedagogi.Mereka memahami prinsip-prinsip teori yang mendasari otonomi pelajar dan praktik-praktik dalam peristiwa kelas sehari-hari yang muncul dari teori yang mendasarinya.Ketiga, terampil dalam manajemen.Mereka dapat mengelola kelas di mana siswa berpartisipasi secara aktif dalam pengambilan keputusan dan dalam penggunaan berbagai strategi dan bahan yang bermanfaat bagi mereka. Mereka dapat mengamati siswa dengan pandangan untuk meningkatkan gaya belajar individu mereka, dan dalam membantu mereka mengatasi tingkat ketidakpastian dalam proses pembelajaran sehari-hari.

\section{Metode}

a. Pendekatan dan Jenis Penelitian

Penelitian ini berdasarkan pendekatanMixd Methods. Langkah dalam penelitian ini menggunakan dua gabungan penelitian yaitu pendekatan penelitian kualitatif dan kuantitatiuf.seringkali disebut dengan Penelitian Campuran atau kombinasi. Yang bertujuan agar data yang dihasilkkan dapat lebih komprehensif dalam mendalami masalah dikarenakan peneliti akan bebas menggunakan alar pengumpulan data sesuai dengan kebutuhan data.

Kunatitatif dan kualitatif mempunyai kekurangan dengan instrument pengumpulan data yang terbatas. Menurut (Creswell, 2014: 5) Mixed Methods adalah suatu desain penelitian yang didasari asumsi filosofis sebagaimana metoda inkuiri. Mixed methods research juga disebut sebagai sebuah metodologi yang memberikan asumsi filosofis dalam menunjukkan arah atau memberi petunjuk cara pengumpulan data dan menganalisis data serta perpaduan pendekatan kuantitatif dan kualitatif melalui beberapa fase proses penelitian. Peneltian kombinasi (Mixd Metods) merupakan kegiatan yang dilakukan bersamaan dalam sebuah penilitain tunggal atau berseri sehingga analisi data yang didapatkan lebih valid, reliable dan obyektif dengan lebih komprehensif. 
Batasan yang tegas dan jelas dalam penelitan kualitatif dan kuantitatif adalah terkait sumber, analisis dan instrument pengumpulan dan dapat membuat beberapa data tidak dapat terpenuhi dan komprhensif. Dan mixed metods berada sebagai jalan tengah dari dua paradigm penelitian tersebut. Dengan menggabungkan kedua intrumen pengumpul data seperti wawancara, observasi langsung ataupun tidak, kuisioner dan studi dokumen maka penelitan akan dapat memperkuat keabsahan data tersebut melalu dua analisis yang berbeda. Hasil kuisioner yang diperkuat dengan wawancara mendalam akan memdapatkan hasil penelitian yang maksimal.

Penelitian kombinasi mixed metods didasari oleh Premis sentral dalam mengungkapkan data single study (penelitian tungal) tentang pembelajaran mandiri Autonomous Learning pada mahasiswa pendidikan bahasa Arab Universitas Jambi. Penelitian kombinasi dipilih agar lebih memberikan pemahaman mendalaman terkait data penelitian dengan melibatkan dua fungsi dari dua pendekatan secara kolektif. Dengan memberikan gambaran deskriftif atas hipotesis tertentu dari gejala atau variabel keadaan tertentu.

b. Subjek Penelitian

Subjek penelitian terdiri dari mahasiswa, dosen dan pihak yang terlibat dalam pelaksanaan pembelajaran mandiri di prodi pendidikan bahasa arab Universitas Jambi yang dalam penetapannya menggunakan purposive samping, menurut (Joko 2008 :31) yaituteknik pengambilan sampel dari sumber data dengan pertimbangan tertentu. Pertimbangan tertentu ini, misalnya orang tersebut yang dianggap paling tahu tentang apa yang kita harapkan, atau mungkin dia sebagai penguasa sehingga akan memudahkan penelii menjelajahi obyek/situasi sosial yang diteliti dan mahasiswa sebagai informan kunci, dosen dan pihak terkait sebagai informan tambahan.

c. SumberData

Sumber data pada penelitan ini terbagi dua jenis: primer dan sekunder. Sumber data primer penelitian ini adalah hasil wawancara, angket/kuisioner dari mahasiswa prodi pendidikan bahasa arab universitas jambi. Dan demikian jug hasil wawancara dengan stackholder terkait seperti dosen dan teman sejawat yang mendukung data penelitian. 
Data sekunder dalam penelitian ini adalah dokumen-dokumen yang berkaitan dengan proses pelaksanaan pembelajaran mandiri mahasiswa prodi pendidikan bahasa arab universitas jambi. Seperti poto kegiatan dan instrument pembelajaran lainnya. Dan data sekunder lainnya diambil dari dokumen yang relevan seperti jurnaljurnal serta karya ilmiah dan data pendukunng lainnya

d. Teknik Pengumpulan Data

Menurut (Burhan, 2010) teknik pngumpulan data penelitian kombinasimixed metods adalah dengan cara observasi, kuesioner, wawancara dan dokumentasi.

1) Observasi

Observasi adalah proses pengamatan terhadap suatu objek. Dan dalam penelitan ini observasi yang digunakan adalah observasi tidak terstruktur. Menurut (Burham, 2010) observasi tidak terstruktur yang digunakan dengan guide observasi sehingga pengamat harus mampu mengembangkan daya pengamatannya dalam melihat suatu objek.

2) Kuesioner/Angket

Kuisioner merupakan daftar dari beberapa pertanyaan mengenai suatu masalah yang diteliti.Dengan kuisioner ini bertujuan untuk mendapatkan informasi dari sekelompok orang tentang permaslahan yang diteliti. Menurut Arikunto (2006: 12)

Kuisoner yang digunakan dalam penelitian ini adalah jenis kuisioner tertutup dengan menggunakan (18) butir pertanyaan terkait dengan pembelajaran mandiri yang dilakukan mahasiswa pendidikan bahasa Arab Universitas Jambi. Kuisoner ini menggunkan skala likert yang nantinya berisi pilhan jawaban dari pertanyaan yang disampaikan lewat google form.Dan pengisian tersebut melibatkan seluruh mahasiswa semester genapPendidikan Bahasa Arab sebagai partisipan.Pengisian kuisoner /angket tertutup tersebut meliputi tujuh aspek pembelajaran mandiri yang diasumsikan sebagai aspek mendasar pembelajaran mandiri.

3) Wawancara

Menurut (Burham, 2010) wawancara sebgai proses memperoleh keterangan untuk tujuan penelitian dengan Tanya jawab sambil bertatap muka dengan sumber data. Dan wawancara tersebut dilakukan kepada beberapa mahasiswa sebagai sampel 
penelitian pada prodi pendidikan bahasa arab. Serta pihak terkait (teman sejawat, ustad dan guru les dll.Dimana pemebelajaran mandiri dilaksanakan.

4) Dokumentasi

Studi dokumentasi bertujuan untuk mengumpulkan data dengan mengumpulkan dan menganalisis dokumen -dokumen baik tertulis maupun non tertulis sepeti gambar dan elektronik terkait historis ataupun proses pembelajaran mandiri dilaksanakanan. Sebagai data pendukung dari sebuah observasi terhadap sesuatu yang berkaitan dengan penelitian.

e. Pengolahan dan Analisis Data

Dalam pengolahan dan analsisis data penelitian ini terbagi dua yaitu, Pertama analsisis data kualitatif dan analaisis data kuantitatif. Untuk data wawancara dan obsrvasi dianalsiss dengan pendekatan kualitatif sedangkan hasil angket dianalisis dengan pendekatan kuantitatif menggunakan statistik deskriftif sedehana software SPSS 16.

Proses analsis data kualitatif menurut (Miles and Huberman 1992) data kualitatif diperoleh dari reduction, display dan classification dan conclusion drawing/verification.

Dan data yang dihasilkan dari observasi, kuisioner dan wawancara serta dokumentasi dianalisis dan disajikan dalam bentuk uraian secara bersamaan.Menurut (Creswell, 2011) Dengan gabungan dua metode penelitian dengan desain penelitian sequential explonatori.Dan analisis data kuantitatif dijadikan sebagai metode utama dan analisis data kualitatif menjelaskan lebih dalam tentang data kuantitatif

\section{Autonomous Learning dan Merdeka Belajar Bahasa Arab}

Hasil dan luaran yang dicapai sesuai dengan tema penelitian yang berjudul :Autonomous Learning: Manifestasi Merdeka Belajar Bahasa Di Prodi Pendidikan Bahasa Arab dengan beberapa bahasan yaitu : (1) Gambaran Umum dan Latar Belakang (2). Hasil dan Luaran yang Telah dicapai pada penelitian ini. Dan akan disajikan secara singkat, jelasdan terarah.

a. Gambaran Umum dan Latar Penelitian

Penelitian ini dilakukan di Program Studi pendidikan Bahasa Arab , Jurusan Pendidikan Bahasa dan Sastra Fakultas Keguruan ILmu Pendidikan FKIP. Sebelum di integrasikan, Prodi PBA ini adalah 
bagian dari Prodi yang ada di Fakultas Ilmu Budaya FIB Universitas Jambi. Prodi Ini Awal dibukanya adalah kesusasteraan Arab tetapi setelah diajukan ke Kemenristek Dikti yang diterima dan disetujui adalah Prodi bahasa arab yang berbasis Pendidikan .

b. Hasil dan Luaran yang dicapai

Dari berdasarkan kajian teori yang telah dijelas pada bab sebelumnya. Maka hasil dan luaran pada bagian ini haruslah mengacu kepada kerangka kajian teori tersebut agar tidak keluar dari pembahasan tema penelitian ini. Dan penelitan ini menggunkan model mixed metods didalmnya dua kerangka Penelitian yaitu, kuantitatif dan kualitatif yang datanya diambil dari angket yang telah disebarkan melalui google form dan dianalisis dengan indikator pokok dari Autonomous Learning meliputi :

1) Kesadaran mahasiswa

2) Usaha mandiri

3) Kegiatan yang menyangkut otonom yang lebih luas

4) Kepercayaan diri

5) Penggunaan bahan referensi

6) Motivasi

7) Penggunaan teknologi dalam pembelajaran

Seluruh indikator tersebut memliki statemen yang berbeda-beda dengan keseluruhan statemen berjumlah 18 statemen yang mencerminkan nilai masing-masing indikator. Dan dibawah ini akan disajikan dan dipaparkan data yang didapatan dilapangan terkait dengan indikator pembelajran mandiri Autonomous Learning tersebut.

c. Faktor Dominan dalam Autonomous Learning

1) Kesadaran mahasiswa 


\begin{tabular}{l|l|c|c|c|c|c|c}
\hline No. & \multicolumn{1}{|c|}{ Statements } & $\begin{array}{c}\text { Never } \\
\text { (\%) }\end{array}$ & $\begin{array}{c}\text { Rarely } \\
\text { (\%) }\end{array}$ & $\begin{array}{c}\text { Sometimes } \\
\text { (\%) }\end{array}$ & $\begin{array}{c}\text { Often } \\
\text { (\%) }\end{array}$ & $\begin{array}{c}\text { Always } \\
\text { (\%) }\end{array}$ & Mean \\
\hline $\mathbf{1 .}$ & $\begin{array}{l}\text { Saya pikir saya } \\
\text { memiliki kemampuan } \\
\text { untuk belajar Bahasa } \\
\text { Arab dengan baik. }\end{array}$ & 0 & 9.7 & 36.3 & 37.2 & 16.8 & 3.61 \\
\hline $\mathbf{2 .}$ & $\begin{array}{l}\text { Saya menetapkan } \\
\text { tujuan pembelajaran } \\
\text { saya. }\end{array}$ & 0 & 6.2 & 23.0 & 37.2 & 33.6 & 3.98 \\
\hline $\mathbf{3 .}$ & $\begin{array}{l}\text { Saya memanfaatkan } \\
\text { waktu luang saya } \\
\text { dengan belajar Bahasa } \\
\text { Arab. }\end{array}$ & 0 & 7.1 & 50.4 & 35.4 & 7.1 & 3.42 \\
\hline
\end{tabular}

Berdasarkan akumulasi mean dalam aspek "Kesadaran Mahasiswa" didapati bahwasanya kesadaran mahasiswa bahasa Arab dalam otonomi pembelajaran berada pada level tinggi yaitu 3.67. Hal tersebut diperkuat dengan kemampuan yang mahasiswa miliki untuk belajar bahasa Arab dengan baik (3.61), dan juga terkait poin kesadaran mahasiswa dalam menetapkan tujuan pembelajaran (3.98), yang mana dua hal tersebut juga menunjukkan pada level tinggi. Sementara kesadaran mahasiswa bahasa Arab dalam memanfaatkan waktu luang mereka dengan belajar bahasa Arab berada pada level menengah yaitu 3.42. Data tersebut juga didukung dengan beberapa alasan pemilihan bahasa Arab sebagai program studi yang dituju mahasiswa, yaitu sebagai berikut

"Keinginan kakak kandung dan seperti almarhumah kakak ipar". (AH)

"Alasannya Karena Saya Suka Pelajaran Bahasa Arab Dari Saya Smp-Sma, Jadi Saya Memilih Jurusan Bahasa Arab Di Universitas Jambi" (DS) 
"Agar saya bisa memahami arti dari ayat Al-Qur'an dan fasih dalam membaca Al-Qur'an". (BD)

Dapat disimpulkan bahwasanya motivasi dari orang sekitar, kecintaan terhadap pelajaran bahasa Arab, dan bahasa Arab sebagai bahasa Al-Qur'an merupakan alasan yang mendasari tingginya kesadaran mahasiswa. Adapun kita-kiat yang mahasiswa lakukan untuk menunjang kemandiriannya dalam berbahasa Arab yaitu dengan melakukan beberapa aktivitas di luar pembelajaran, yaitu sebagai berikut:

"Terkadang mengulas pelajaran, menonton, dan menulis". (AH)

"Sedikit-Sedikit Menghafal Kosa Kata Dan Mengulangi Pelajaran Waktu Di Kelas". (DS)

"Banyak yang saya lakukan, salah satunya adalah melihat video percakapan bahasa Arab lewat YouTube”. (BD)

"Banyak yang saya lakukan, salah satunya adalah melihat YouTube". (RK)

Dari hasil wawancara, mahasiswa melakukan pengulangan belajar kembali terkait materi yang diberikan oleh dosen mereka di kelas dan didukung dengan penggunaan media seperti youtube.

2) Usaha mandiri

\begin{tabular}{|c|l|c|c|c|c|c|c|}
\hline No & \multicolumn{1}{|c|}{ Statements } & $\begin{array}{c}\text { Never } \\
\text { (\%) }\end{array}$ & $\begin{array}{c}\text { Rarely } \\
\text { (\%) }\end{array}$ & $\begin{array}{c}\text { Sometimes } \\
\text { (\%) }\end{array}$ & $\begin{array}{c}\text { Often } \\
\text { (\%) }\end{array}$ & $\begin{array}{c}\text { Always } \\
\text { (\%) }\end{array}$ & Mean \\
\hline $\mathbf{4 .}$ & $\begin{array}{l}\text { Saya mempelajari } \\
\text { topik pelajaran yang } \\
\text { akan dipelajari } \\
\text { sebelum masuk kelas. }\end{array}$ & 0 & 11.5 & 46.0 & 36.3 & 6.2 & 3.37 \\
\hline $\mathbf{5 .}$ & $\begin{array}{l}\text { Di kelas, saya } \\
\text { mencoba } \\
\text { menggunakan setiap } \\
\text { kesempatan untuk } \\
\text { mengambil bagian } \\
\text { dalam kegiatan di } \\
\text { mana saya dapat } \\
\text { berbicara dalam } \\
\text { Bahasa Arab. }\end{array}$ & 3.5 & 18.6 & 46.9 & 26.5 & 4.4 & 3.10 \\
\hline
\end{tabular}




\begin{tabular}{|l|l|c|c|c|c|c|c|}
\hline 6. & $\begin{array}{l}\text { Saya berbicara } \\
\text { dengan penuh } \\
\text { percaya diri di } \\
\text { depanorang-orang. }\end{array}$ & 3.5 & 22.1 & 38.9 & 22.1 & 13.3 & 3.19 \\
\hline 7. & $\begin{array}{l}\text { Saya membuat catatan } \\
\text { dan ringkasan } \\
\text { pelajaran saya. }\end{array}$ & 0.9 & 4.4 & 19.5 & 38.9 & 36.3 & 4.05 \\
\hline $\mathbf{8 .}$ & $\begin{array}{l}\text { Saya berbicara dengan } \\
\text { Dosen dan teman di } \\
\text { luar kelas dalam } \\
\text { Bahasa Arab. }\end{array}$ & 8.8 & 42.5 & 43.5 & 4.4 & 0.9 & 2.46 \\
\hline Grand Mean & & & & & & \\
\hline
\end{tabular}

Berdasarkan data, didapati bahwasanya aspek "Usaha Mandiri" yang dilakukan mahasiswa bahasa Arab dalam menunjang mereka untuk menjadi pembelajar mandiri dikategorikan ke dalam level menengah (3.23). Menariknya, dari beberapa poin ya mengau pada usaha mandiri mahasiswa, poin no 7, mengenai "membuat catatan dan ringkasan pelajaran saya" adalah poin yang paling menonjol dari semua aspek "usaha mandiri", yaitu berada pada level tinggi (4.05). Sebaliknya, poin no 8, mengenai "berbicara dengan dosen dan teman di luar kelas dalam bahasa Arab" berada pada level rendah yaitu 2.46. Sebagaimana yang dijelaskan dalam salah satu wawancara kepada partisipan, yaitu:

"Saya melihat kembali catatan di buku atau melihat file-file yang dikirim dosen sebelumnya lewat aplikasi". (BD)

Dari hasil wawancara kepada partisipan, melihat kembali catatan di buku dan file-file yang diberikan dosen adalah salah satu pengamalan mahasiswa dalam mewujudkan usaha kemandiriannya.

3) Kegiatan yang menyangkut otonom yang lebih luas

\begin{tabular}{|l|l|c|c|c|c|c|c|}
\hline No. & \multicolumn{1}{|c|}{ Statements } & $\begin{array}{c}\text { Never } \\
\mathbf{( \% )}\end{array}$ & $\begin{array}{c}\text { Rarely } \\
\mathbf{( \% )}\end{array}$ & $\begin{array}{c}\text { Sometimes } \\
\mathbf{( \% )}\end{array}$ & $\begin{array}{c}\text { Often } \\
\mathbf{( \% )}\end{array}$ & $\begin{array}{c}\text { Always } \\
\text { (\%) }\end{array}$ & Mean \\
\hline 9. & $\begin{array}{l}\text { Saya berlatih Bahasa } \\
\text { Arab di luar kelas } \\
\text { seperti: merekam suara } \\
\text { saya sendiri; berbicara }\end{array}$ & 7.1 & 27.4 & 40.7 & 20.4 & 4.4 & 2.88 \\
\hline
\end{tabular}




\begin{tabular}{|l|l|c|c|c|c|c|c|}
\hline & $\begin{array}{l}\text { dengan orang lain dalam } \\
\text { Bahasa Arab. }\end{array}$ & & & & & & \\
\hline $\mathbf{1 0 .}$ & $\begin{array}{l}\text { Saya menggunakan } \\
\text { perpustakaan untuk } \\
\text { meningkatkan Bahasa } \\
\text { Arab saya. }\end{array}$ & 17.7 & 42.5 & 24.8 & 9.7 & 5.3 & 2.42 \\
\hline $\mathbf{1 1 .}$ & $\begin{array}{l}\text { Saya menggunakan } \\
\text { materi audio-visual } \\
\text { untuk mengembangkan } \\
\text { pidato saya seperti: } \\
\text { mendengarkan BBC, } \\
\text { menonton film } \\
\text { berBahasa Arab, } \\
\text { mendengarkan musik, } \\
\text { membaca koran/majalah } \\
\text { berBahasa Arab dll. }\end{array}$ & 2.7 & 14.2 & 39.8 & 36.3 & 7.1 & 3.31 \\
\hline $\mathbf{1 2 .}$ & $\begin{array}{l}\text { Saya menghadiri berbagai } \\
\text { seminar, kursus, } \\
\text { pelatihan, konferensi, } \\
\text { komunitas untuk } \\
\text { meningkatkan Bahasa } \\
\text { Arab saya. }\end{array}$ & 10.6 & 23.9 & 37.2 & 21.2 & 7.1 & 2.90 \\
\hline $\mathbf{1 3 .}$ & $\begin{array}{l}\text { Saya mengambil risiko } \\
\text { dalam mempelajari } \\
\text { Bahasa Arab. }\end{array}$ & 5.3 & 11.5 & 32.7 & 28.3 & 22.1 & 3.50 \\
\hline Grand Mean & & & & & & & \\
\hline
\end{tabular}

Berdasarkan hasil data dari total keseluruhan mean terhadap indikator no tiga, yaitu kegiatan yang menyangkut otonom lebih luas, dapat disimpukan bahwasanya dalam indikator ada pada level medium (3.00). Dalam aspek ini, kesadaran siswa untuk berlatih bahasa Arab di luar kelas, penggunaan materi audio-visual, mengikuti seminar, kursus, pelatihan, konferensi, komunitas untuk meningkatkan bahasa Arab berada pada level menengah yaitu antara jumlah mean 2.5-3.4. Sementara itu, berdasarkan data kuesioner, mahasiswa mengaku bahwasanya mereka sering (28.3\%) untuk mengambil risiko dalam mempelajari bahasa Arab, dan hanya 5.3\% dari total keseluruhan mahasiswa bahasa Arab yang menggunakan perpustakaan untuk 
meningkatkan bahasa Arab mereka. Hal tersebut dikarenakan:

"Sangat penting sebenarnya, meski awalnya perpustakaan jarang dikunjungi karena masih sulit menemukan buku bahasa arab maka lebih suka dengan teknologi seperti kamus dan aplikasi lainnnya, dua-duanya sama sangat penting untuk penunjang penguasaan pembelajaran". (AH)

Berdsarkan hasil wawancara, didapati salah satu alasan yang menyebabkan rendahnya partisipasi mahasiswa untuk menggunakan perpustakaan adalah karena ketersediaan referensi berbahasa Arab yang belum memadai.

4) Kepercayaandiri

\begin{tabular}{|l|l|c|c|c|c|c|c|}
\hline No. & \multicolumn{1}{|c|}{ Statements } & $\begin{array}{c}\text { Never } \\
\text { (\%) }\end{array}$ & $\begin{array}{c}\text { Rarely } \\
\text { (\%) }\end{array}$ & $\begin{array}{c}\text { Sometimes } \\
\text { (\%) }\end{array}$ & $\begin{array}{c}\text { Often } \\
\text { (\%) }\end{array}$ & $\begin{array}{c}\text { Always } \\
\text { (\%) }\end{array}$ & Mean \\
\hline 14. & $\begin{array}{l}\text { Saya mencatat kekuatan } \\
\text { dan kelemahan saya } \\
\text { dalam belajar Bahasa } \\
\text { Arab dan } \\
\text { meningkatkannya }\end{array}$ & 4.4 & 12.4 & 35.4 & 32.7 & 15.0 & 3.42 \\
& & & & & & & \\
\hline
\end{tabular}

Dalam indikator "Kepercayaan diri" mahasiswa bahasa Arab dapat dikategorikan memiliki level medium untuk mencatat kekuatan dan kelemahan mereka dalam belajar bahasa Arab dan meningkatkannya. Sekitar 32.7\% mahasiswa yang dikategorikan sering untuk menganalisa kekurangan dan kelebihan mereka dalam pembelajaran. Hal itu didukung dengan pernyataan salah satu mahasiswa, yang mengatakan:

"Kelemahan saya banyak namun tidak menutup kemungkinan kekuatan saya di istima' bisa ditingkatkan”. $(\mathrm{AH})$

5) Penggunaan bahanreferensi

\begin{tabular}{|c|c|c|c|c|c|c|c|}
\hline No. & Statements & $\begin{array}{c}\text { Never } \\
\mathbf{( \% )}\end{array}$ & $\begin{array}{c}\text { Rarely } \\
\mathbf{( \% )}\end{array}$ & $\begin{array}{c}\text { Sometimes } \\
\mathbf{( \% )}\end{array}$ & $\begin{array}{c}\text { Often } \\
\mathbf{( \% )}\end{array}$ & $\begin{array}{c}\text { Always } \\
\mathbf{( \% )}\end{array}$ & Mean \\
\hline 15. & $\begin{array}{l}\text { Saya membaca kembali } \\
\text { pelajaran dan mencari }\end{array}$ & 1.8 & 8.0 & 36.3. & 44.2. & 9.7 & 3.52 \\
\hline
\end{tabular}




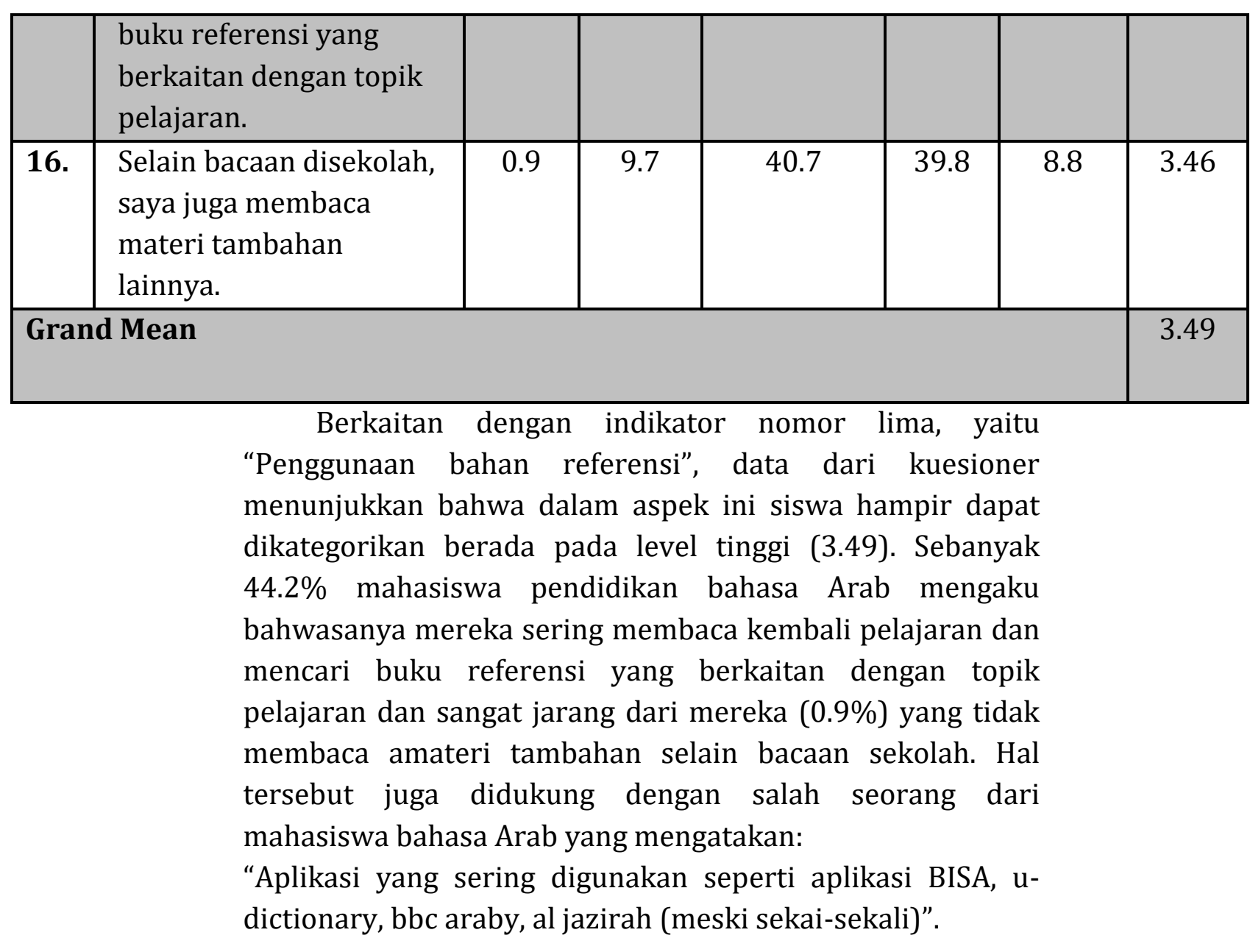

6) Motivasi

\begin{tabular}{|c|c|c|c|c|c|c|c|}
\hline No. & Statements & $\begin{array}{l}\text { Never } \\
(\%)\end{array}$ & $\begin{array}{c}\text { Rarely } \\
(\%)\end{array}$ & $\begin{array}{c}\text { Sometimes } \\
\text { (\%) }\end{array}$ & $\begin{array}{c}\text { Often } \\
(\%)\end{array}$ & $\begin{array}{c}\text { Always } \\
\text { (\%) }\end{array}$ & Mean \\
\hline 17. & $\begin{array}{l}\text { Ketika saya membuat } \\
\text { kemajuan dalam belajar, } \\
\text { saya menghargai diri } \\
\text { sendiri seperti: membeli } \\
\text { barang baru, merayakan } \\
\text { pesta, dll. }\end{array}$ & 34.5 & 21.2 & 23.9 & 16.8 & 3.5 & 2.34 \\
\hline & $\begin{array}{l}\text { Indikator } \\
\text { motivasi siswa } \\
\text { membuat kema } \\
\text { dan memberik } \\
\text { menunjukkan } \\
\text { dikategorikan } r\end{array}$ & $\begin{array}{l}\text { nomor } \\
\text { rkait ba } \\
\text { lan dala } \\
\text { rewar } \\
\text { ahwa } \\
\text { ndah }(2 \text {. }\end{array}$ & $\begin{array}{l}\text { enam } \\
\text { gaimana } \\
\text { belajar } \\
\text { terhad } \\
\text { 34). Han as }\end{array}$ & $\begin{array}{l}\text { aitu berkait } \\
\text { xemampuan } \mathrm{m} \\
\text { menghargai } \\
\text { ap dirinya se } \\
\text { pek ini res } \\
\text { ya } 3.5 \% \text { maha }\end{array}$ & $\begin{array}{l}\text { n den } \\
\text { ereka al } \\
\text { liri senc } \\
\text { ndiri. D } \\
\text { on sis } \\
\text { siswa y }\end{array}$ & & \\
\hline
\end{tabular}


mengaku pernah memberikan penghargaan pada diri mereka sendiri. Adapun alasannya adalah sebagai berikut:

"Selama ini ketika kemampuan meningkat tidak ada yang dibeli atau diberi hadiah untuk sebuah penghargaan diri sendiri hanya rasa syukur dan biasa saja". (AH)

"Saya beli buku-buku yang terdapat dalam bahasa Arab, misalnya kamus fi'il,kamus jamak taksir, buku percakapan bahasa Arab dan lain-lain". (BD)

Dari alasan kedua maahsiswa tersebut, terdapat perbedaan pandangan bagaimana cara mereka untuk menghargai diri mereka.

7) Penggunaan teknologi dalam pembelajaran

\begin{tabular}{llcccccc}
\hline No. & \multicolumn{1}{c}{ Statements } & $\begin{array}{c}\text { Never } \\
\text { (\%) }\end{array}$ & $\begin{array}{c}\text { Rarely } \\
\text { (\%) }\end{array}$ & $\begin{array}{c}\text { Sometimes } \\
\text { (\%) }\end{array}$ & $\begin{array}{c}\text { Often } \\
\text { (\%) }\end{array}$ & $\begin{array}{c}\text { Always } \\
\text { (\%) }\end{array}$ & Mean \\
\hline 18. & $\begin{array}{l}\text { Saya menggunakan } \\
\text { internet dan komputer } \\
\text { untuk belajar dan } \\
\text { meningkatkan Bahasa }\end{array}$ & 0.9 & 0 & 18.6 & 43.4 & 37.2 & 4.16 \\
& & & & & & & \\
Arab. & & & & & & \\
\hline
\end{tabular}

Indikator nomor tujuh berkenaan dengan penggunaan teknologi dalam pembelajarn yang mana meliputi aspek penggunaan interner dan komputer untuk belajar dan meningkatkan bahasa Arab. Data menunnjukkan pada poin ini, respon mahasiswa dikatakan berada pada leve tinggi (4.16), yang mana $43.4 \%$ mahasiswa mengaku sering dalam penggunaan internet. Hal trsebut juga dapat didukung oleh penyataan mereka dalamw wawancara, yaitu sebagai berikut:

"Sangat berguna dimana dizaman era digital ini banyak sekali manfaat dari teknologi tersebut seperti menonton dan mendengar music arab dan saya merasa ada manfaatnya meski fokus kadang terganggu, terkait majalah dan Koran untuk saat ini akan sulit ditemukan namun masih ada manfaatnya". (AH). 


\section{Kesimpulan}

Berdasarakan hasil penelitian dalam pembahasan ini, dapat ditarik kesimpulan bahwa secara umum pembelajaran mandiri Autonomous Learning. Yang dilakukan mahasiswa diluar kelas menunjukkan rata- rata pada level tinggi dan menengah yang didapati pada faktor dominan dari indikator pertanyaan kuesioner sebagai berikut :

1. Kesadaran mahasiswa pada level tinggi (3.67)

2. Usaha mandiri pada level menengah (3.23)

3. otonom yang lebih luas pada Level Medium (3.00)

4. Kepercayaan diri pada Level Menengah (3.42)

5. Penggunaan bahan referensi pada Level Tinggi (3.49)

6. Motivasi pada level rendah (2.34)

7. Penggunaan teknologi dalam pembelajaran pada Level Tinggi (4.16) Mahasiswa memiliki level otonomi yang tinggi pada saat penggunaan teknologi dalam pembelajaran. Sebalikany, mahasiswa dikategorikan memiliki level otonomi yang rendah di bagian motivasi, yang mana mereka jarang memberikan penghargaan pada diri mereka sendiri dalam pembelajaran bahasa arab di prodi pendidikan bahasa arab universitas jambi 


\section{Daftar Pustaka}

Ahmadi, Razieyeh. (2013). Iranian ESP learners' perception of autonomy in language learning. International Journal of Applied Linguistics\&English Literature, 2(1), 28-34.

Ajzen, I. (2005). Attitudes, personality and behavior (2nd ed.). New York: Open University Press.

Benson, P. (2007). Autonomy in language teaching and learning. Language teaching, 40 (1), 21-40.

Chan, V. (2001). Readiness for learner autonomy: What do our learners tell us? Teaching in Higher Education, 6(4), 505-519.

Cotterall, S. (1995). Readiness for autonomy: Investigating learner beliefs. System, 23(2), 195205.

Creswell, J. W. 2003. Research design: quantitative, qualitative, and mixed methods approaches. USA: Thousand Oaks.

Dickinson, L. (1987). Self-Instruction in language learning. Cambridge: Cambridge University Press.

Harmer, Jeremy. (2007). The practice of english language teaching. Malaysia: Pearson Education Limited.

Johnson, Keith. (2001). An introduction to foreign language learning and teaching. England: Pearson Education Limited.

Joshi, Khem Raj. (2011). Learner perceptions and teacher beliefs about learner autonomy in language learning. Journal of NELTA, 16(1-2), 1329.

Littlewood, W. (1999). Defining and developing learner autonomy in East Asian contexts.

Applied Linguistics, 20(1), 71-94.

Oxford, R. L. (1990). Language learning strategies: What every teacher should know. Boston: Heinle \& Heinle.

Robson, C. (1993). Real world research: a resource for social scientists and practitioners-researchers. Oxford: Blackwell

Sakai, Shie, et.al. (2010). Promoting learner autonomy: student perceptions of responsibilities in a language classroom in east asia. Educational Perspective, 43 (1-2), 12-21.

Sinclair, B. (2000). Learner autonomy: The next phase? In B. Sinclair, I. McGrath \& T. Lamb (Eds.), Learnerautonomy, teacher autonomy: Future directions. Harlow: Longman. 
